\title{
D ECUPERANDO DEL OLVIDO A ARTISTAS VALENCIANOS: EL CASO DEL PINTOR ANTONIO VIVÓ NOGUERA (1772- ca. 1834)
}

MARÍA JOSÉ LÓPEZ TERRADA

Universitat de València M.Jose.Lopez@uv.es

\begin{abstract}
Resumen: Existen un buen número de diseñadores y pintores que estudiaron en la Sala y Escuela de Flores de la Academia de San Carlos de Valencia de los que apenas se tiene algunos datos documentales y cuya producción se desconoce casi por completo. Entre ellos se encuentra el artista Antonio Vivó Noguera (Valencia, 1772 - ca. 1834). En el presente artículo se analizan y dan a conocer varias obras inéditas del autor que demuestran que no solo fue un excelente pintor de flores, sino que también cultivó otros géneros pictóricos. Se dan asimismo a conocer obras del artista relacionadas, tanto con su proceso académico de formación y su participación en los Concursos Generales, como su labor artística posterior, lo que amplía la visión limitadísima y parcial que se ha tenido de este autor hasta el momento.
\end{abstract}

Palabras clave: Antonio Vivó / Academia de Bellas Artes de San Carlos de Valencia / siglos XVIII y XIX / Pintura de Flores / Pintura religiosa / Obras inéditas / Mercado artístico.

Abstract: Many of the designers and painters who studied at the Sala y Escuela de Flores (School of Floral Painting) at the Academy of San Carlos in Valencia are almost completely unknown. Among these is Antonio Vivó Noguera (Valencia, $1772-c a$. 1834). This article brings to light a number of his previously unknown drawings and paintings; an analysis of these works demonstrates that Vivó Noguera was not only an excellent painter of floral still life, but also cultivated other genres. This article also examines the works of artists of the same circle, including their academic training and successes in painting competitions, as well as their subsequent artistic production. This article deepens our heretofore limited understanding of Vivó Noguera and his world.

Key words: Antonio Vivó / San Carlos Academy of Fine Arts (Valencia) / Eighteenth and Nineteenth Centuries / Floral still-life painting / Religious painting / Unknown Works / Art market.

El objetivo del presente artículo es contribuir al conocimiento de la producción de uno de los múltiples artistas valencianos que desarrollaron su actividad entre los años finales del siglo XVIII y principios del XIX. Hasta el momento, la historiografía tradicional solo había considerado a Antonio Vivó como uno de los múltiples artistas pertenecientes a la Escuela valenciana de Flores. En esta ocasión, no solo se analizan sus dibujos y un óleo de flores integrándolos en su trayectoria académica, sino que también se recogen o dan a conocer otras obras de Vivó pertenecientes tanto a su proceso de formación y a su participación en los Concursos Generales, como a su producción posterior. Con ello se pone de manifiesto que sus aspiraciones no se limitaron únicamente a convertirse en pintor de flores -género por el que se le recordaría-, sino que fueron mucho más amplias.

Durante el último tercio del siglo XVIII hasta principios del siglo XIX, Valencia se convirtió en un importante centro de formación de diseñadores textiles y pintores de flores cuyo origen está directamente relacionado con la proyección económica que, desde comienzos de la centuria, había experimentado la industria valenciana de la seda. La llegada de los Borbones a España había supuesto un cambio en los gustos de la Corte y la imposición progresiva de la moda francesa e italiana. Este hecho, unido a la precaria situación en que se encontraba la industria textil española desde los

* Fecha de recepción: 15 de abril de 2017 / Fecha de aceptación: 20 de junio de 2017. 
años finales del siglo XVII, motivó que para cubrir las necesidades del nuevo ambiente cortesano se recurriera a la importación de tejidos extranjeros procedentes principalmente de Lyon. La necesidad de formar diseñadores textiles capaces de crear modelos originales para los tejidos y fomentar la independencia de Valencia respecto a las sederías lionesas determinó la creación por parte de Carlos III de la Sala de "Flores, Ornatos y otros diseños adecuados para los Tejidos" en la Real Academia de Bellas Artes de San Carlos en 1778. El establecimiento definitivo de la "Escuela de Flores y Ornatos aplicados a los tejidos" se produjo seis años más tarde, a partir de la Real Orden de 1784. En ella, el monarca equiparó oficialmente estos estudios en rango, dotación y dignidad a las restantes enseñanzas académicas y se nombró como Director al "Maestro de Flores" Benito Espinós (17481818), que sería el responsable de los mismos hasta su jubilación en 1815. A este período corresponde la época de mayor prestigio de la Escuela. Su actividad se prolongó hasta 1855, año en que la materia fue sustituida por los estudios de dibujo lineal y adornos. ${ }^{1}$

El modelo educativo desarrollado desde su creación, que respondía en origen a un proyecto típico de la llustración, solo logró convertirse parcialmente en un estímulo para la industria textil y otras manufacturas valencianas. ${ }^{2}$ Sin embargo, formó a un numeroso y excelente grupo de pintores de flores que, con el tiempo, se convirtieron en los artistas más personales e innovadores del género en España. En 1997, Pérez Sánchez ya señalaba que:

Puede hablarse, sin duda, de una escuela local de pintores especialistas que constituye un capítulo significativo en la historia del género, aunque la dispersión de sus obras en colecciones particulares de difícil acceso, la escasez de estimación que ha mostrado hacia ellos el "gusto moderno", y lo limitado de su presencia en las obras de carácter general, consecuencia de los escasos ejemplos que podían verse en los museos públicos, han hecho de ellos verdaderos desconocidos que solo en estos últimos tiempos empiezan a descubrirse. [...] Solo el resurgir del interés por este tipo de pintura y la inteligente gestión de marchantes y anticuarios, podrán poner en circulación obras seguras, firmadas y datadas de estos artistas nada desdeñables, que muestran en su obra, decorativa y superficial si se quiere, pero evidentemente hábil y segura en su técnica y sorprendentemente, bien próxima a cuanto se hacía en los mismos años en Francia, Holanda y Austria, países en los que la pintura de flores de raíz dieciochesca mantuvo, como en Valencia, su vigencia y estimación hasta muy entrado el siglo XIX. ${ }^{3}$

El contacto con coleccionistas particulares y la aparición en el mercado artístico de composiciones autógrafas de estos artistas está contribuyendo efectivamente a ampliar poco a poco el conocimiento todavía insuficiente de la producción de la Escuela valenciana de Flores. ${ }^{4}$ Es el caso del lienzo de flores de Antonio Vivó Noguera que ahora se analiza, una obra de calidad y en estado óptimo de conservación y de la Sagrada Familia. No obstante, como se ha adelantado, el objetivo del presente artículo es más amplio, pues también se consideran otras obras de Vivó pertenecientes a su proceso académico de formación, a su participación en los Concursos Generales y a su producción posterior. Lamentablemente, la mayor parte de estos trabajos, mencionados en testimonios o documentos de la época no se han conservado.

La primera mención a Antonio Vivó como "pintor de flores y adornos" figuró en la obra de Vicente Boix Noticias de los artistas valencianos del siglo $X I X$, de 1877. En ella se indicaba que el artista, nacido en Valencia en 1772, participó en los concursos de la Academia de San Carlos durante los años 1789, 1792 y 1798, consiguiendo en los dos últimos "las medallas de segunda y primera clase por la pintura de flores y adornos" para tejidos. Añadía asimismo que en el actual Museo valenciano

\footnotetext{
1 ALDANA, Salvador, 1970; LÓPEZ TERRADA, María José, 1998 y 2001, donde se recoge la bibliografía anterior. Entre las últimas aportaciones puede citarse la obra de SÁNCHEZ, Andrés, 2008, aunque su estudio solo llega hasta 1818.

2 A pesar de la productiva relación de algunos diseños académicos con la industria sedera durante el siglo XVIII, una de las razones principales de "este estímulo parcial" fue que los académicos de San Carlos nunca llegaron a entender el alcance de la intención con la que Carlos III creó estos estudios, que podría haber convertido los talleres tradicionales en una industria moderna con profesionales especializados. Por otra parte, parece oportuno señalar que los numerosos artistas formados en esta Sala también contribuyeron a renovar los motivos de la azulejería seriada valenciana de las últimas décadas del siglo XVIII. Véase: PÉREZ GUILLÉN, Inocencio Vicente, 1996, pp. 181-182 y FELIU, Joan, 1998, que también menciona como fuente de inspiración los dibujos de Antonio Vivó en las pp. 178, 180 y 355.

3 PÉREZ SÁNCHEZ, Alfonso Emilio, 1997, pp. 36-37.

${ }^{4}$ Véanse, por ejemplo, las aportaciones del mencionado estudio de SÁNCHEZ, Andrés, 2008; los artículos de LÓPEZ TERRADA, María José, 2000, sobre Francisco Michans (1777 - post 1837) o los de la misma autora de 2013 y 2016, sobre la pintura de flores de Miguel Parra (1780-1846).
} 
de Bellas Artes se conservaban "dos floreros suyos", ${ }^{5}$ hoy desaparecidos. Esta misma información fue fielmente recogida por Ossorio y Bernard en su Galería biográfica de artistas españoles del siglo XIX (ed. 1883); por el Barón de Alcahalí, autor del Diccionario biográfico de artistas valencianos (1897), así como por el Conde de la Viñaza en sus Adiciones al Diccionario histórico de los más ilustres Profesores de Bellas Artes en España de D. Juan Agustín Ceán Bermúdez (1889-1894). ${ }^{6}$ Estos escasos datos pasaron sin modificación al estudio y catálogo ilustrado de la gran exposición organizada por Cavestany en 1935 dedicada a la pintura de flores y bodegones españoles de los siglos XVII al XIX. ${ }^{7}$ Hubo que esperar al trabajo que Aldana realizó en 1970 sobre los pintores valencianos de flores a partir de las fuentes documentales de la Academia de San Carlos para que estas pocas referencias fueran ampliadas. Las noticias que proporciona, junto a otros datos que aparecen un tanto dispersos en su estudio, ${ }^{8}$ la recopilación de nuevas noticias y la revisión realizada de los dibujos que actualmente se conservan en el Museo de Bellas Artes de Valencia han permitido ir concretando las distintas etapas de la formación académica de Antonio Vivó.

El artista, cuyo nombre completo es Graciano Antonio Vivó Noguera, ingresó a los diez años, en decir, en 1782, en la Sala de Principios de la Academia de San Carlos. ${ }^{9}$ Como es sabido, el aprendizaje del dibujo llamado "de formación" comprendía tres niveles: la Sala de Principios; la del Yeso o del "modelo blanco" y, finalmente, la del Natural, que el joven alumno debía ir superando de forma progresiva. Este sistema pone de manifiesto la importancia que, desde el Renacimiento, siempre se concedieron al dibujo y al estudio de la anatomía humana. Una vez que concluía toda esta fase de aprendizaje, podía pasar a una etapa más avanzada en la que debía enfrentarse con el llamado "dibujo histórico", es decir, aquél donde tenía que desarrollar todos los recursos aprendidos: volúmenes, composición, perspectiva, etcétera. ${ }^{10}$

Los discípulos de la Academia comenzaban pues su aprendizaje con los llamados Estudios de Principios, que comprendían los "Estudios de perfiles". Eran llamados de esta forma porque un trazo continuo servía para siluetear el contorno y la copia de partes aisladas del cuerpo humano, como manos, orejas, pies o cabezas. Durante esta etapa, utilizaban como modelos dibujos o estampas realizados por artistas ya consagrados destinados a este fin. El primer dibujo, desde el punto de vista cronológico, de Antonio Vivó que se conserva en el Museo de Bellas Artes de Valencia y que ahora se da a conocer, corresponde a esta fase de formación. Se trata de un Estudio de pie con sandalia realizado con lápiz negro sobre papel blanco de 395 x 300 mm. (fig. 1). Representa un pie izquierdo que descansa en la punta, dejando el talón al aire. Es muy probable que Vivó utilizara como modelo uno de los dibujos realizados por Luis Antonio Planes precisamente para la formación de los alumnos de la Sala de Principios. ${ }^{11}$ Sabemos que, en esta Sala fue premiado en 1785 y $1787 . .^{12}$

5 BOIX, Vicente, 1877, p. 62.

6 OSSORIO Y BERNARD, Manuel (ed.), 1883-1884, p. 702; ALCAHALÍ, Barón de, 1897, p. 330 y VIÑAZA, Conde de la, 1889 1898, vol. IV, p. 58.

7 CAVESTANY, Julio, 1936-1940, p. 99.

8 ALDANA, Salvador, 1970, p. 209. Las referencias a Vivó que aparecen a lo largo de este estudio, fueron revisadas y recogidas en los trabajos de LÓPEZ TERRADA, María José, 1998, vol. II, pp. 553-557; 2001, pp. 265-266 y ALBA, Ester, 2004, vol. III, pp. 2153-2154.

9 Aunque firma como "Antonio Vivó", en uno de los dibujos que se conservan en el Museo de Bellas valenciano a los que aludiré más adelante ( $\mathrm{N}^{\circ}$ de Inv. 10072), figura al dorso, en tinta: "Graciano Antonio Vivó en 3 de mayo de 90". La información sobre sus padres la proporcionó ALDANA, Salvador, 1970, p. 209, precisando que era "hijo de Vicente y Catalina Noguera".

10 Para la importancia del dibujo en la formación del artista puede verse VEGA, Jesusa, 1989, pp. 1-29 y para el caso concreto de esta enseñanza en la Academia de Bellas Artes valenciana, ESPINÓS, Adela, 1984, vol. I, pp. $26-29$.

$11 \mathrm{~N}^{\circ}$ Inv. 11667. El Estudio de pie con sandalia procede, como el resto de dibujos del artista que se conocen, de los fondos de la Real Academia de Bellas Artes de San Carlos. Está firmado por la parte trasera a tinta. Por otra parte, como indicó ESPINÓS Adela, 1984, vol. I, pp. 49-50, el Museo valenciano conserva una serie de treinta y tres dibujos de Luis Antonio Planes de diferentes fragmentos anatómicos (labios, narices, ojos, manos y pies), que tenían como finalidad servir de modelo en la Sala de Principios. El que posiblemente copiara Vivó de Planes se reproduce con el nº 397 en el catálogo de esta autora.

12 La noticia de estos premios fue dada a conocer por ALDANA, Salvador, 1970, p. 209, que además señaló que en 1786 había opositado sin éxito a la $3^{\text {a }}$ clase de Pintura en el Concurso General celebrado aquel año. Este último dato, que hemos asumido todos los que hemos estudiado a Vivó, es un error, como he podido comprobar al consultar la Continuación de las Actas de la Real Academia de las Nobles Artes establecida en Valencia con el título de San Carlos y relación de los premios que distribuyó en 9 de octubre de 1786 publicada en 1787. Los únicos opositores al premio fueron José Esteve, Luis Planes, Rafael Esteve, Jaime Baset, Pedro Vicente Rodríguez y Vicente González, que resultó ganador. 


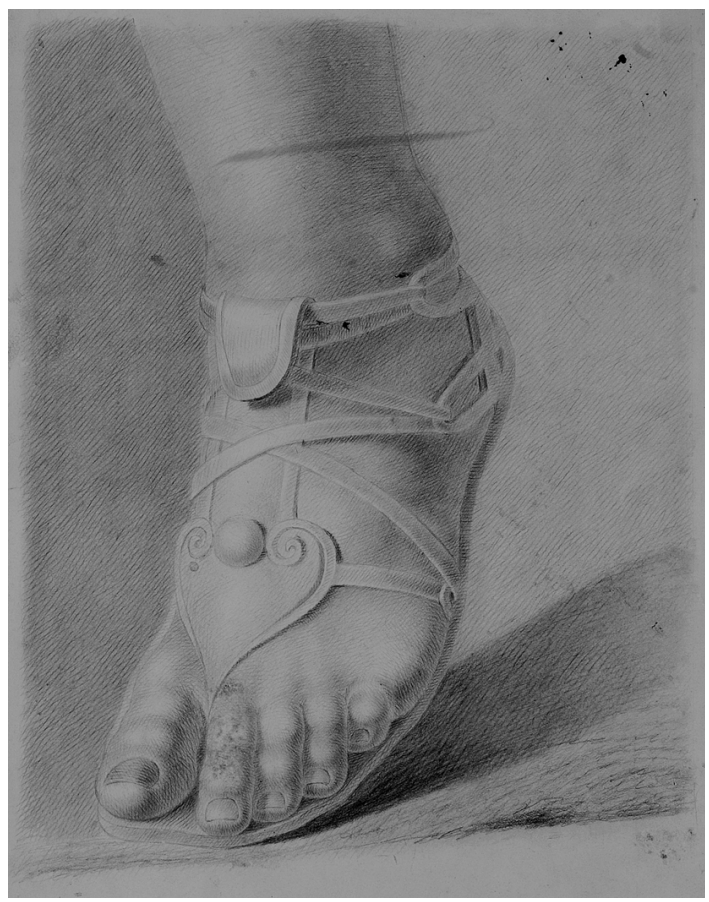

Fig. 1. Antonio Vivó, Estudio de pie con sandalia. Museo de Bellas Artes de Valencia.

Lo que no puede asegurarse es que el dibujo que se reproduce sea el que le valió alguno de los mencionados reconocimientos, pues no hay indicaciones en él que lo corroboren.

La formación de Vivó continuó en la Sala de yeso o del "modelo blanco". En esta etapa de formación, el alumno debía aprender a representar el modelo tridimensional, reflejando, básicamente, los efectos de luces y sombras. Se copiaban aquí primero fragmentos anatómicos para pasar luego a dibujar partes y esculturas completas realizadas en yeso -de ahí su denominación de "modelo blanco"-, que habían sido ejecutadas obteniendo el vaciado de esculturas clásicas. ${ }^{13}$ A esta etapa corresponde el segundo dibujo que se da a conocer. Lleva como título El Premio y también se conserva en el Museo de Bellas Artes de Valencia (fig. 2). Se

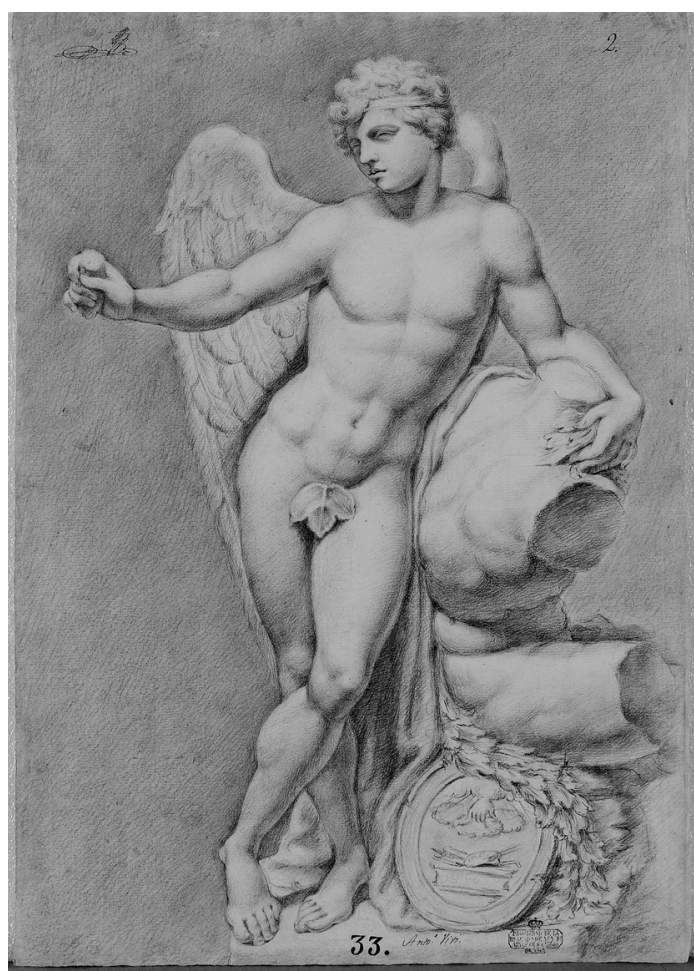

Fig. 2. Antonio Vivó, El Premio. Museo de Bellas Artes de Valencia.

trata de una obra realizada con lápiz y carbón sobre papel verjurado de $546 \times 481 \mathrm{~mm} .{ }^{14}$ Creemos que el modelo utilizado fue la copia del vaciado en yeso de la obra realizada por el escultor francés Roberto Michel (1720-1786) en 1759.15 Esta figura fue regalada por el autor a Manuel Monfort (1763-1806), destacado miembro de las Academias de San Fernando y San Carlos y encargado entonces de los pensionados en Madrid, para que la enviase a la institución valenciana. ${ }^{16}$ La obra representa a un joven desnudo y alado que alza su mano derecha mientras reclina su cuerpo, apoyándose y abrazando con la diestra al torso del Belvedere. Debajo, entre un paño y una rama de laurel, se dispone el emblema de la Academia de San Fernando realizado por Tomás Francisco Prieto, Director de grabado de la institución. Aunque está

${ }_{13}$ Como precisa ESPINÓS, Adela, 1984, vol. I, pp. 26-27, según el Inventario de Yesos de la Academia de San Carlos (17731821), la colección de la Institución comprendía un total de 206 piezas que eran empleadas indistintamente según los criterios fijados por el encargado de dirigir la Sala. La mayor parte de estos modelos habían sido regalados por los propios académicos o por otras Academias, especialmente la de San Fernando.

${ }^{14} N^{\circ}$ Inv.: 10401. Está firmado en la parte inferior: "Anto Vivó".

15 Roberto Michel llegó a ocupar el cargo de Teniente Director de Escultura de la Academia de San Fernando desde 1763 y el de Director General en 1785, consiguiendo además el puesto de Escultor de Cámara de Fernando VI y Carlos III.

${ }^{16}$ En el citado Inventario de Yesos de la Academia de San Carlos (1773-1821) que reproduce ESPINÓS, Adela, 1984, vol. III, pp. 331-339, se menciona el modelo con el $n^{\circ}$ 15: "Un baciado (sic) de la Figura del Premio con sus alas recostado sobre un torso, obra hecha para presentar a la Academia de $S^{n}$ Fernando, y manifestar su mérito $D^{n}$ Roberto Michel, el que regaló este baciado (sic) a $D^{n}$ Manuel Monfort, y este remitió a esta academia". Al margen indica que no existía en 1815. 
mucho más esbozado que el resto, en él vemos tres coronas entrelazadas sostenidas por una mano que sale de la parte superior. Bajo ella, sobre un plinto, aparecen entrecruzados los tres útiles que representan a la Arquitectura (compás), la Pintura (pincel) y la Escultura (cincel). ${ }^{17}$ Así mismo, podemos aportar que Antonio Vivó también recibió en esta Sala una gratificación. Concretamente, obtuvo por todos los votos, el premio mensual del "modelo blanco" en 1787. ${ }^{18}$ Finalmente, pasó a la Sala del Natural, la última etapa del sistema pedagógico del dibujo de formación en la que se realizaba el estudio ante el modelo vivo. Constituía una práctica imprescindible para que un principiante se familiarizara con la anatomía humana. Desgraciadamente no se ha conservado ninguna Academia de Vivó de esta etapa. No obstante, podemos proporcionar una nueva noticia: la recepción del premio mensual de "modelo vivo" el 5 de noviembre de $1790 .{ }^{19}$

Dos años antes, en 1788, siendo alumno de la Sala del Natural, pidió el ingreso a la Sala de Flores. Parece oportuno señalar que en la Real Orden de 1778 que establecía la organización y finalidad de los nuevos estudios de Flores y Ornatos, ya se indicaba claramente que no se admitiría en dicha Sala a ningún discípulo que no supiera ya diseñar las partes del cuerpo humano. ${ }^{20}$ El paso a la Sala, dirigida por Benito Espinós, se hizo efectivo el 12 de octubre de 1778. Vivó fue, por tanto, compañero de generación de artistas como Pascual Soto Xi- meno (1772 - post. 1840), ${ }^{21}$ Joaquín Bernardo Rubert (1772 - post. 1816), ${ }^{22}$ el catalán Salvador Molet (Barcelona, 1773-1836), ${ }^{23}$ Francisco Michans (1777 - post. 1837)24 o José Rosell (1778 - post. 1837). ${ }^{25}$

La Real Orden de 1784 también reguló varios aspectos que merecen ser destacados. En primer lugar, delimitó claramente cuál era la misión y organización de la Escuela, estableciendo que: "Todos los días, a excepción de los festivos, ha de haber dos horas de estudio por la mañana desde el $1^{\circ}$ de Abril hasta el último día de Julio, donde los discípulos estudien, dibujando unos de lápiz, y otros de colorido al pastel, aguadas o al óleo, las flores del natural que produce el tiempo en estos cuatro meses", siendo "de cuenta de la Academia costear y tener prontas las flores que pidiese el mismo Director en dichos cuatro meses". ${ }^{26}$ En 1788, el turno de trabajo se alteró, estableciéndose el inicio de las clases en marzo y finalizándolas en julio. Este cambio se justificó por la variedad de flores que crecían durante estos meses, particularmente las de los árboles frutales, que se consideraron muy adecuadas para la finalidad de estos estudios. Durante la temporada del invierno se debían copiar "originales dibujados y coloridos", siendo cargo y obligación del Director "ordenar y hacer por sí un estudio de flores, sacadas del natural, y ayudadas de los realces del buen gusto y de los adornos; para los cuales la Academia le facilitará las lochas (sic) de Rafael, y otros ejemplares de los

\footnotetext{
17 El tema del dibujo es el mismo que el realizado por Eliseo Camarón Meliá que, al dorso indica: "Se premió esta figura en 1 de Junio de 95; sin embargo de estar borrada la parte posterior de ella, juzgando haber sido maliciosamente hecho por un opositor". Entre los dibujos anónimos del Museo también se conserva otro del mismo asunto, pero realizado desde un punto de vista diferente. Corresponden respectivamente a los números 214 y 1068 del catálogo de ESPINÓS, Adela, 1984.

18 ALDANA, Salvador, 1970, p. 81.

19 "Noticias particulares de Valencia. Nobles Artes". Diario de Valencia, 6 de diciembre de 1790, pp. 267-268: "La Real Academia de San Carlos, en la Junta Ordinaria que celebró el 5 del corriente adjudicó à sus Discípulos los premios mensuales, perteneciente al mes de Noviembre, en la forma que sigue: El de modelo vivo à Antonio Vivó [...]". Documento proporcionado por Ester Alba.

20 1784, enero 30. Valencia. Real Orden por la cual se establece en la Real Academia de San Carlos una Escuela para el estudio del dibujo de Flores y Ornatos. Archivo de la Academia de Bellas Artes de San Carlos de Valencia, Colección de Reales Órdenes (1770-1828). En ALDANA, Salvador, 1970, doc. 4, pp. 267-27, aunque previamente había sido dado a conocer por CAVESTANY, Julio, 1936-1940, doc. VI, p. 140.

${ }^{21}$ Sobre Pascual Soto, ver LóPEZ TERRADA, María José, 1998, vol. II, pp. 532-541; 2001, pp. 258-259. ALBA, Ester, 2004, vol. III, pp. 2085-2089.

22 Sobre Joaquín Bernardo Rubert, ver LÓPEZ TERRADA, María José, 1998, vol. II, pp. 522-526; 2001, pp. 255-256. ALBA, Ester, vol. III, pp. 2070-2073.

${ }^{23}$ Sobre Salvador Molet, ver LÓPEZ TERRADA, María José, 1998, vol. II, pp. 430-438; 2001, pp. 236-237. SÁNCHEZ, Andrés, 2008, pp. 323, 349, 362-370, 568-576, 663-665.

24 Sobre Francisco Michans, ver LÓPEZ TERRADA, María José, 1998, vol. II, pp. 422-429; 2000, pp. 39-44; 2001, pp. 234-235. ALBA, Ester, 2004, vol. III, pp. 1516-1529.

25 Sobre José Rosell, ver LÓPEZ TERRADA, María José, 1998, vol. II, pp. 518-522; 2001, pp. 254-255. ALBA, Ester, 2004, vol. III, pp. 2060-2064.

26 Real Orden, 1784 (ver nota 20).
} 
preciosos restos de la Antigüedad que deberán servirle exclusivamente de norma, a fin de ir formando el gusto de los discípulos". ${ }^{27}$ Entre estas últimas obras se encontraban el tomo primero de $L a$ Pitture antiche d'Ercolano e contorni: incise con qualche spriegazione (Nápoli, 1757) de Ottavio Antonio Baiardi, que el propio Carlos III regaló a la Academia y que posteriormente serían completados con otros volúmenes. La institución, por su parte, adquirió en 1791 varias obras que servirían para el diseño ornamental, en especial para los jarrones de las composiciones florales, como la Suite de vases, dessinés par Petitot et gravés par Rossi (1764) y Raccolta de vasi diversi formati da illustri artefici e di varie targhe soprapposte alle fabriche, grabadas por Filippo de Rossi (Roma, 1713). ${ }^{28}$ La Real Orden también reguló la concesión de premios y ayudas económicas en los siguientes términos:

Queriendo S. M. que esta facultad sea tratada con el mismo honor y decoro que todas las demás de la Academia, deberá ésta en los Concursos Generales de premios dar tres en todo iguales a los de la Pintura. [...] Estos premios serán votados por los mismos vocales que los de la clase de Pintura, y distribuidos de la misma forma. Con el fin de exercitar la aplicación de los discípulos de este Estudio dispondrá la Academia se den tres ayudas de costas al concluir la temporada de primavera, y otras tres al concluir la del invierno, de cantidad igual a las que da la Academia en el $\mathrm{Na}$ tural, Yeso y Principios. [...] A los mismos discípulos a quienes todos los años se adjudiquen las tres ayudas de costa de la temporada de primavera, y las otras tres de la del invierno, se les asistirá con la pensión siguiente diaria: a los primeros de tres reales; a los segundos de dos; y los terceros de uno; sirviéndoles aquel ejercicio de oposición para obtener estas plazas, con la advertencia de que los que las ocupen no hayan de poder retener las pensiones respectivas más tiempo que el de un año, bien que los que gocen las segundas podrán pasar a las primeras, y progresivamente los de las terceras a las de otras si por su mérito y aplicación lo merecieran; pero jamás deberá verificarse que posea ninguna de estas pensiones más de un año un mismo sujeto. Por este medio circulará de unos a otros; y el deseo de obtenerla, y el de ascender los que ya tienen una inferior a otra mayor, como también el continuo ejercicio de las oposiciones, estimulará y tendrá en útil movimiento, y seguida aplicación a estos jóvenes. ${ }^{29}$
Por último, la mencionada Real Orden también tenía en cuenta a los profesores dedicados a esta disciplina, disponiéndose que la Academia podía ir premiando y honrando con los grados de Académicos Supernumerarios y de Mérito a los que acreditasen una habilidad sobresaliente.

Las siguientes noticias inéditas relativas a las aspiraciones de Vivó corresponden al año 1789, en las que se presentó a dos convocatorias. La primera corresponde a un premio extraordinario para becar a los dos discípulos más destacados de la clase de Pintura, Escultura, Arquitectura o Grabado para estudiar en la Corte "por tiempo de tres años, instruyéndose en los buenos Originales de que hay tanta abundancia en aquella Corte", meta ansiada por todo aspirante a artista. ${ }^{30}$ Como se dispuso en la Junta Ordinaria de la Academia del 2 de noviembre de 1788 que redactó la convocatoria del concurso, para optar a él los alumnos no debían tener más de veinte años. El concurso se abrió el 1 de diciembre, dándose de tiempo para firmar cuatro meses, y seis para realizar las obras. Los asuntos para la pintura, a los que opositaron Antonio Vivó, Luis Planes y Vicente López, consistieron en representar al óleo el tema "Tobías el Joven restablece la vista a su Padre", además de dibujar en doce noches un grupo "de Modelo vivo y Maniquí vestido dispuesto a este fin". Los tres artistas, a excepción de Luis Planes, que no pudo concluir sus obras a tiempo por motivos de salud, realizaron además en la Academia el ejercicio "de repente" durante dos horas. Tenía como asunto el "Ángel anuncia a Zacarías el nacimiento del Bautista". Entre los participantes en las distintas disciplinas, quedaron finalistas por la pintura Antonio Vivó y Vicente López, que acabaría consiguiendo la pensión por todos los votos, mientras que Rafael Esteve la obtuvo por el Grabado.

La segunda convocatoria a la que se presentó nuestro artista corresponde al Concurso General de 1789, es decir, al mismo año, en el que opositó sin éxito a la tercera Clase de Pintura. ${ }^{31}$ Como es sabido, las obras que los opositores debían presentar en este tipo de certámenes eran de dos tipos. Los primeros asuntos que se determinaban y hacían públicos seis meses antes constituían los ejercicios "de pensado". Tras ser examinados por la Junta General correspondiente se acordaban los temas para los ejercicios "de

27 Real Orden, 1784 (ver nota 20).

28 SÁNCHEZ, Andrés, 2008, pp. 322-323. Para un conocimiento más amplio de los fondos de la Biblioteca de San Carlos, resultan imprescindibles los capítulos de ALDANA, Salvador, 2004, pp. 33-51 y 2009, pp. 277-290.

29 Real Orden 1784 (ver nota 20).

30 Para los detalles de este premio y sus fuentes ver DíEZ, José Luis, 1999, vol. I, pp. 40-42, nota 46.

31 CONTINUACIÓN, 1789, p. 14. 
repente", que debían llevarse a cabo en la Academia. Se disponía para ello de dos horas y los dibujos se realizaban en papeles iguales, rubricados por el secretario y no se firmaban. Los tres premios que correspondían a cada clase se adjudicaban a partir de los votos obtenidos y se entregaban en una Junta Pública convocada para ello. ${ }^{32}$ Vivó participó junto a Francisco Roda, Mariano Torra, Pedro Vicente Rodríguez y Rafael Esteve, que obtuvo este galardón y el de escultura de la misma categoría. Los ejercicios "de pensado" y "de repente" consistieron en dibujar, respectivamente, "la Estatua del Apolo Phitio Belvedere que está en la Academia" y "la figura del Pastor de la Cabra", obras que no se conservan. ${ }^{33}$

Como discípulo de la Sala de Flores tuvo más éxito, pues el 3 de mayo de 1790, consiguió la tercera pensión, noticia que ya se ha mencionado. Parece interesante integrar esta gratificación en el contexto en el que se produjo. Desde su creación, la Sala de Flores y Ornatos fue objeto de conflicto en numerosas ocasiones en el seno de la propia Academia. Los ataques de los profesores de pintura, que siempre consideraron el Estudio de flores como algo secundario frente a las restantes disciplinas académicas fueron constantes, temiendo también que sus enseñanzas se supeditasen a las directrices del Colegio del Arte Mayor de la Seda. En varios momentos, los propios discípulos fueron los que se negaron a seguir realizando dibujos adaptables a la industria sedera, pues preferían tratar la flor natural. En estas discusiones se mezclan no solo cuestiones artísticas, sino también sociales. Los pintores de flores, que iban adquiriendo un cierto prestigio y estimación entre la sociedad burguesa, no se contentaban con ser simplemente artesanos al servicio de una manufactura que, a pesar de los esfuerzos de Carlos III, seguía siendo vista en determinados círculos como un simple oficio manual. Incluso a su Director, Benito Espinós, se le acusó de favorecer unas enseñanzas más artísticas que aplicadas al no limitarse a adaptar los estudios de flores a los tejidos, despreciando esta práctica mecánica. Por su parte, los Mayorales del Colegio del Arte Mayor de la Seda insistían en la necesidad de proporcionar a los fabricantes dibujos aplicados a los tejidos. La si- tuación empeoró en 1790, al no poderse conceder la pensión y la ayuda de costa de primera clase debido a la escasa calidad de las obras presentadas. En efecto, en este año, las gratificaciones de mayor rango quedaron desiertas, mientas que las segundas fueron adjudicadas a José Zapata (1763-1837) -que llegaría a ocupar el puesto de Director de la Escuela de Flores tras la jubilación de Espinós y el cargo de Director general de la Academia-, y la tercera, como se ha señalado, a Antonio Vivó.

Actualmente podemos hacernos una idea de la tarea realizada por Vivó en esta época bajo las enseñanzas de Espinós, pues entre los dibujos del artista conservados en el Museo de Bellas Artes de Valencia se encuentran tres diseños para ser aplicados al tejido por los que obtuvo esta gratificación. Todos llevan en el ángulo inferior derecho el $n^{\circ} 40$, que se corresponde con la entrada del Inventario de las pinturas, flores pintadas y dibuxadas (sic) ... de la Academia de San Carlos, de 1797-1834. ${ }^{34}$ El primer Modelo para tejido consiste en una cenefa con motivos decorativos en cuyo centro se dispone un grupo de flores. Está realizado en aguada de color rojo y azul sobre papel verjurado blanco con el contorno teñido de rosa. Mide 510 x $359 \mathrm{~mm}$. y en el ángulo inferior derecho, a tinta puede leerse: "Vivó durante la Pensión de 3 de mayo de 90", además de su firma a sanguina. El segundo modelo es una cenefa horizontal con un ángel sobre un dosel, un pájaro, una mariposa, pebeteros y guirnaldas florales. Para este dibujo empleó aguada negra y roja sobre preparación inicial a lápiz en papel verjurado. Mide 512 x $432 \mathrm{~mm}$. Estos dibujos con diferentes motivos decorativos fueron ideados posiblemente para una basquiña. El último, ejecutado con lápiz negro y tiza sobre papel verdoso gris, mide 530 x $405 \mathrm{~mm}$. Es más complejo y está más próximo en su disposición a las Logias de Rafael, pues está compuesto por cenefas verticales. El centro lo ocupa una armadura y otros elementos militares sobre los que se posa un águila, rematándose en la parte superior por una espada y una trompeta entrelazadas. Este eje central lo termina en su base un amplio racimo de flores sostenido por dos figuras femeninas. A su alrededor se despliegan varias guirnaldas florales. ${ }^{35}$

32 ESPINÓS, Adela, 1997, p. 84.

33 CONTINUACIÓN, 1789.

${ }^{34}$ En el Inventario..., bajo en $n^{\circ} 40$, se dice: "En cinco papeles, los dos azules con flores del natural, y los tres de esquises para fábricas de texidos, obras para la oposición de pensiones de 3 de Mayo de 90 y por dos de ellos se le adjudicó la segunda de dos reales a Josef Zapata y por los tres restantes la tercera de real a Antonio Vivó, habiendo quedado vacante la de tres reales". ALDANA, Salvador, 1970, p. 305.

35 El último dibujo, Modelo para tejido: cenefa con motivos ornamentales de flores, figuras y trofeos es el que está firmado al dorso, a tinta "Graciano Antonio Vivó en 3 de mayo de 90". Entre otras obras, se reproducen en ESPINÓS, Adela, 1997, n 82, p. $265 ; n^{\circ} 83$, p. 266 y n 84, p. 267. 


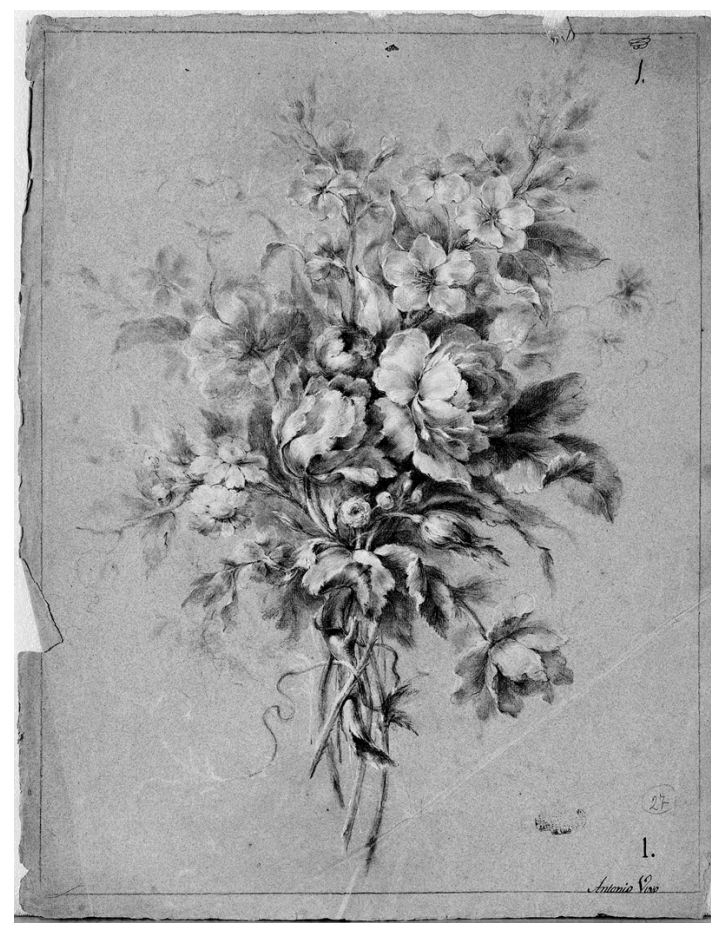

Fig. 3. Antonio Vivó, Estudio de flores, 1791. Museo de Bellas Artes de Valencia.

En noviembre de 1790 se examinaron las obras de los dos pensionados, las cuales tenían que presentar periódicamente, teniendo la obligación de que los asuntos fueran adaptables a los tejidos. Se informó que ambos jóvenes hacían grandes adelantos en su especialidad. Sin embargo, sorprendentemente, Vivó manifestó que no quería continuar con la pensión. Esto supuso que se le entregase, sin oposición, la primera pensión a Zapata, dejando vacantes las otras dos hasta que los discípulos de las restantes secciones alcanzasen mayores méritos. ${ }^{36}$

Todo indica que los intereses de Vivó iban más allá de su formación exclusiva en la Sala de Flores, pues durante este mismo año -1790-, recibió los premios mensuales de mayo y diciembre por varios dibujos realizados en la Sala de Escultura ${ }^{37}$ que actualmente desconocemos.

Además de los dibujos aplicados a los tejidos ya mencionados, Vivó realizó también otras obras en

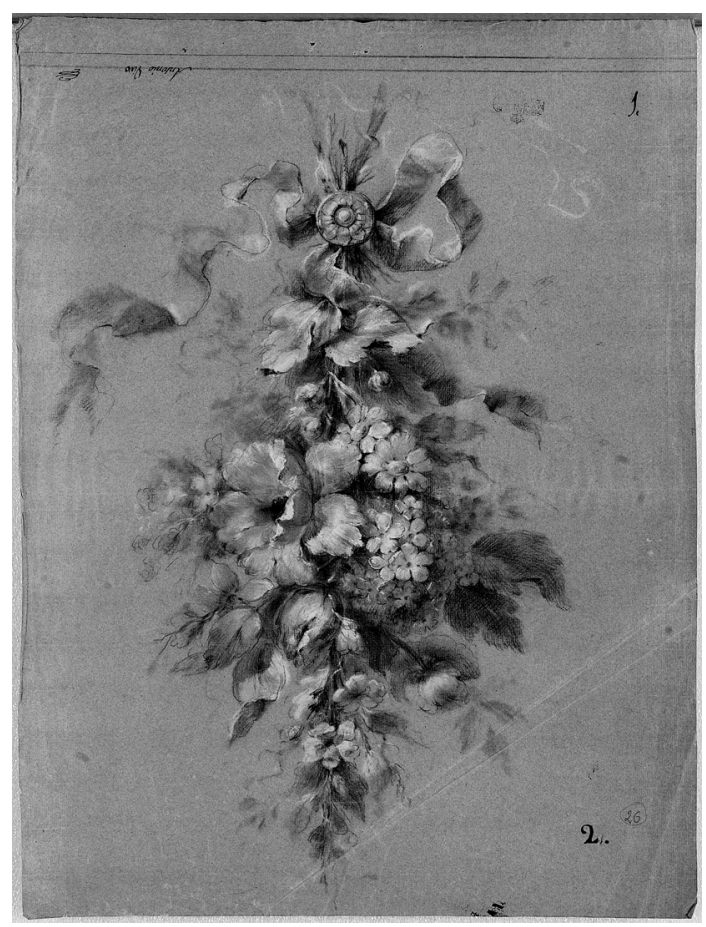

Fig. 4. Antonio Vivó, Estudio de flores, 1791. Museo de Bellas Artes de Valencia,

la Sala de Flores fechadas el 1 de mayo de 1791 que se conservan en el Museo de Bellas Artes de Valencia. Son dos Estudios de flores que damos a conocer, pues no han sido publicados. Ambos reflejan su dominio en la representación de especies ornamentales del natural. El primer dibujo, realizado con lápiz negro y tiza sobre papel verjurado, mide $532 \times 420$ mm. (fig. 3). ${ }^{38}$ Se trata de un ramo de flores compuesto por peonías, tulipanes, margaritas, flores de almendro, alhelíes, anémonas y la flor conocida como botón de oro (Ranunculus acris L.). El segundo Estudio de flores (fig. 4), para el que empleó también lápiz negro y tiza sobre papel verjurado, mide $545 \times 410 \mathrm{~mm} \cdot{ }^{39} \mathrm{En}$ este caso, el ramo presenta una disposición distinta, pues aparece como una colgadura sostenida por una adorno y lazada típicos de los estudios florales de esta época. Entre las especies botánicas representadas se pueden distinguir nuevamente margaritas, un cultivar de peonía, bolas de nieve, tulipanes y la rama de un árbol frutal con flores en dis-

\footnotetext{
36 ALDANA, 1970, p. 89, nota 102.

${ }^{37}$ Acuerdos en limpio de Juntas Ordinarias desde 1787 hasta 1800 (3 de mayo y 5 de diciembre de 1790). En: ALDANA, 1970, p. 209.

${ }^{38} N^{\circ}$ Inv.: 10062. Está firmado en el ángulo inferior derecho a tinta: "Antonio Vivó" y lleva el número "1". A lápiz, en el extremo derecho, figura en $n^{\circ}$ "27". Está fechado al dorso.

${ }^{39} \mathrm{~N}^{\circ}$ Inv.: 10063. Está firmado a tinta y, con diferente orientación, en los ángulos derechos superior e inferior, lleva los números "1" y "2", junto al "26" a lápiz. Como el anterior, está fechado al dorso.
} 
tintos estados de desarrollo. Podemos añadir el dato que la calidad de las obras ejecutadas por Vivó para esta Sala quedó nuevamente refrendada con la concesión del premio mensual del mes de abril de $1791,{ }^{40}$ año en el que también consiguió la segunda pensión en flores, además de ser galardonado en la Clase de Pintura el 20 de noviembre.

Como se ha venido insistiendo, las aspiraciones de Vivó eran muy amplias. Así lo pone igualmente de manifiesto que se presentara en el Concurso General de 1792 a los premios de $2^{\text {a }}$ Clase de Pintura, Flores y Escultura. Ante esta situación, que incurría en un "caso flagrante de incompatibilidad", la Junta de la Academia dictaminó que se le adelantase el examen de Flores "para desembarazarse de esta disciplina, teniendo en cuenta que era el único opositor a esta categoría". ${ }^{41}$ Gracias a la consulta de las Actas publicadas este mismo año, ${ }^{42}$ es posible dar a conocer las obras que Vivó tuvo que realizar en cada una de estas secciones y quienes fueron sus contrincantes. El tema "de pensado" de la $2^{\text {a Clase de }}$ Pintura fue "Abigail contiene la indignación de David con abundante presente", siendo el ejercicio "de repente": "Meleagro presenta la cabeza del Jabalí a Atlanta". Los opositores fueron Vivó, José Aparicio, Joaquín Llop y Vicente Lluch, que consiguió el galardón. Para optar a la $2^{\text {a }}$ Clase de Escultura, realizó como tema "de pensado": "Job en el muladar es visitado de tres amigos" y como "repente" "Jacob ve en sueños una Escala mística". En esta ocasión se presentó junto a Joaquín Doménech, Mariano Guerada, Vicente Llácer, Tomás Llovet y José Esteve y Vilella, que resultó ganador. En la $2^{\text {a }}$ Clase de Flores Vivó fue el único participante, obteniendo esta recompensa a los 19 años. Como tema "de pensado" realizó: "un Dibuxo de dos palmos de alto, y un palmo y quarto de ancho, para Tafetán espolinado a arbitrio, campo listado, y algunas faxas de pelillos que no excedan de dos cuerpos. $Y$ un Florero de dos palmos y medio, y dos palmos, pintado al óleo o al agua, copiado del natural". Como "repente", un jarrón "con Flores naturales que había prevenido a este fin". Parece interesante señalar que el Florero y el dibujo del tafetán que constituyeron el ejercicio "de pensado" estuvieron expuestos en la Sala de Flores entre los cuadros y dibujos de Espinós y otros discípulos aventajados como Pedro Pascual Calado (1758 - post 1808), Benito Senent (1746 - post 1791), Joaquín Carrá (1756 post 1789), Jaime Baset (1762 - primera mitad del siglo XIX), Vicente Pompey (1766 - post 1787), Antonio Colechá (1746 - 1828), Dionisio Medina del Pomar (doc. 1778 - ?), Juan Bautista Romero (1756 1804), Blas Grifol (1777 - ?) y José Antonio Zapata (1763 - 1837). ${ }^{43}$ De las obras realizadas para el Concurso de 1792, incluyendo las de la $2^{\text {a }}$ Clase de Pintura y Escultura, solo se conserva en la actualidad el dibujo realizado como ejercicio "de repente" (fig. 5). Titulado por Aldana como Estudio de flores. Jarrón de flores, está dibujado con lápiz negro y tiza sobre papel verjurado de $440 \times 318 \mathrm{~mm} .{ }^{44}$ En él, las plantas se disponen en un sencillo recipiente que parece de cristal. Entre las flores, mucho más esbozadas que en los dibujos anteriores debido a las características de la prueba, pueden reconocerse narcisos dobles, tulipanes y jazmines.

Dado el deseo de reconocimiento de Vivó y sus múltiples intereses, es difícil explicar su ausencia en el Concurso General celebrado en 1795 en el que no se presentó a ninguna categoría. ${ }^{45}$ Sí lo hi-

40 "Noticias particulares de Valencia. Nobles Artes". Diario de Valencia, 4 de mayo de 1791: "La Real Academia de San Carlos, en la Junta Ordinaria, que celebró el 1 del corriente, adjudicó a sus Discípulos los premios mensuales al mes de abril, en la forma siguiente: [...] el de adornos y flores a Antonio Vivó". Documento facilitado por Ester Alba. Se trata de otra noticia no integrada en su trayectoria hasta el momento.

${ }^{41}$ ALDANA, Salvador, 1970, p. 92.

${ }^{42}$ CONTINUACIÓN, 1792.

${ }^{43}$ Como indicó ALDANA, Salvador, 1970 p. 82, la Sala de Flores de la Academia compartía en esta época la enseñanza con la de Matemáticas en la Universidad de Valencia. Sobre estos artistas, pueden verse los estudios de este autor y de LÓPEZ TERRADA, María José, 2001. Por otra parte, en la Relación de las obras de asunto floral contenidas en el Inventario de las pinturas, flores pinturas y dibuxadas... de la Academia de San Carlos de Valencia, 1797-1834, aparece con el n 12. "Un florero pintado al óleo de dos palmos y medio y dos de ancho, con marco orlado y un dibujo de tafetán matizado, de dos palmos y uno y un cuarto de ancho, obra de don Antonio Vivó por las cuales se le adjudicó el premio de segunda clase en el Concurso del mismo 92", indicándose que el dibujo no existía en 1815.

${ }^{44} N^{\circ}$ Inv.: 1244. Entre otras obras se reproduce en: LÓPEZ TERRADA, María José, 1998, p. 557 y ESPINÓS, Adela, 1997, p. 99. En el ángulo superior derecho, aparece a tinta " $1^{\circ "}$ y la rúbrica. En el inferior izquierdo, puede leerse: "Repente de $2^{\mathrm{a}}$ Clase. Antonio Vivó 92" y "24". El último número corresponde al de la Relación de las obras de asunto floral... 1787-1834, ya citada, en la que se dice: "Otro medio pliego azul de un ramo de flores copiado por el natural, en el repente de segunda clase del concurso de 92 y por él y por las dos obras 'de pensado' bajo el n 12 se adjudicó el premio de dicha segunda clase a Antonio Vivó".

${ }^{45}$ Este dato lo hemos obtenido consultado la Continuación de las Actas de la Real Academia de las Nobles Artes establecida en Valencia con el título de San Carlos y relación de los premios que se distribuyó en 6 de noviembre de 1795. En la Oficina de D. Benito Monfort. Impresor de la Academia, 1796. 


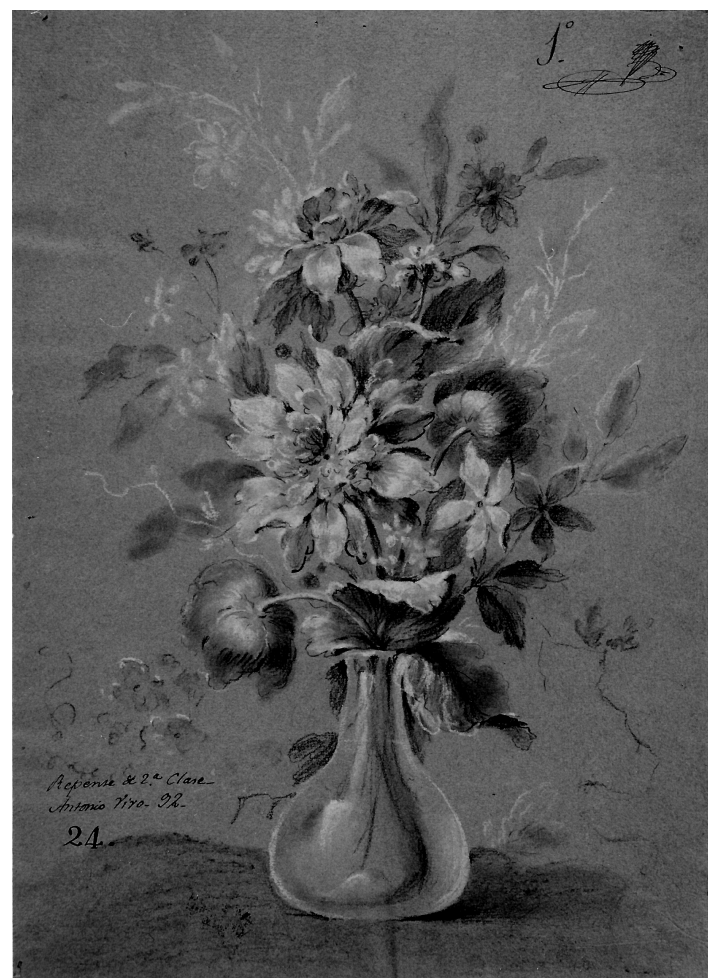

Fig. 5. Antonio Vivó, Estudio de flores. Jarrón de flores, 1792. Museo de Bellas Artes de Valencia.

zo, y con éxito, en el de 1798, pues obtuvo por unanimidad el premio de 40 pesos de la $1^{\text {a }}$ Clase de Flores a los 26 años. En esta convocatoria, el asunto del ejercicio "de pensado" fue "un Dibuxo para un Frontal de Altar Mayor, con Cenefa, por el estilo de las Lochas de Rafael, para fábrica de espolín de sedas de colores y metales; y un Florero pintado al óleo o al agua", mientras que el ejercicio "de repente" consistió en "un dibujo para un Cubrecáliz, con flores y adornos, por gusto de las Lochas". ${ }^{46}$ Llama la atención que en esta ocasión prevalezca, incluso en los ejercicios "de repente", para los que habitualmente se elegía un estudio de flores del natural, el sentido práctico de su

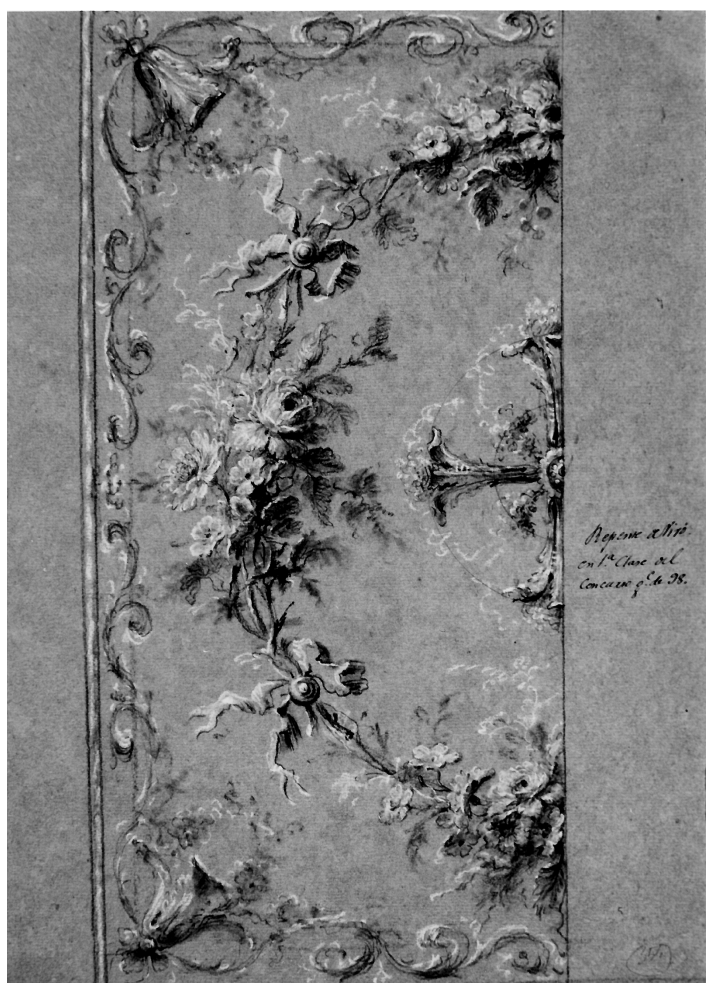

Fig. 6. Antonio Vivó, Modelo para tejido: cenefa vertical con guirnalda de flores, 1798. Museo de Bellas Artes de Valencia.

aplicación al tejido. ${ }^{47}$ Precisamente este último ejercicio, un modelo para tejido con una cenefa vertical con guirnalda de flores, es el único que se conserva en el Museo de Bellas Artes valenciano (fig. 6), ${ }^{48}$ que puede darnos una idea de cómo eran este tipo de diseños. Se trata de un dibujo realizado con lápiz negro y tiza sobre papel gris de $510 \times 327 \mathrm{~mm}$. Este cubre cáliz presenta en el extremo derecho central la mitad de una elaborada cruz rodeada de forma concéntrica por guirnaldas de flores entrelazadas, para lo que se ha utilizado el mismo motivo con lazos de otros dibujos. El borde vertical izquierdo, unido a los superiores e inferiores, lo componen roleos sucinta-

\section{${ }^{46}$ CONTINUACIÓN, 1799}

47 Como explican ALDANA, Salvador, 1970, p. 96 y ESPINÓS, Adela, 1997, p. 102, por la nueva variante que se había introducido en la mecánica de la oposición de los premios de Flores, los "repentes", propuestos por el profesorado serían en adelante pura invención del opositor, pero insistiéndose expresamente en que fuesen los diferentes motivos decorativos de las Logias de Rafael la fuente de referencia a seguir. Ambos reproducen el "repente" en sus estudios respectivamente con el ${ }^{\circ} 371$, p. 251, lám. 57 y nº 85, p. 268.

${ }^{48}$ NN$^{\circ}$ Inv.: 9837. En la Relación... de 1797-1824, las obras realizadas para este concurso aparecen con los números 52 y 55 . Bajo el primero se recogía: "Un florero de dos palmos y tres palmos p. (sic) con vareta dorada pintado al óleo, y un dibuxo para frontal de mesa de altar, adoptado a fábrica de espolín de sedas, de colores y metales. Obras de don Antonio Vivó por las cuales se le adjudicó el premio primero en el concurso de 1798". Con el $n^{\circ}$ 55: "un medio pliego de papel azul en el que halla dibuxado de lápiz un cubre cáliz por el estilo de las lochas, dado por asunto en la primera clase de flores en el repente del concurso del 98 , por el cual y las dos obras de pensado bajo el $n^{\circ} 52$ se le adjudicó el premio primero a Vivó". ALDANA, Salvador, 1970 , p. $251, n^{\circ} 370$, recogió en su trabajo un dibujo que representaba Motivos litúrgicos con guirnalda de flores que correspondía al realizado como ejercicio "de pensado". Actualmente no se conserva. 
mente descritos unidos en los ángulos por motivos acampanados de apariencia vegetal.

En las Juntas donde se entregaban públicamente los premios de los Concursos Generales se recitaban también discursos, poesías y canciones, además de ser muy frecuente los elogios a la Academia de Bellas Artes y a sus protectores, el recuerdo a la Historia artística valenciana o las directrices que debían seguir los alumnos. ${ }^{49}$ La sesión del 6 de diciembre de 1798 fue la más solemne de las celebradas, dada la relevancia de las personalidades que se encontraban en ella. Sin embargo, lo que nos interesa destacar por la relación que guarda con la pintura de flores y por la excepcionalidad que representa dentro de la mentalidad académica, más inclinada al idealismo, es un fragmento de la poesía escrita para la ocasión por Don Pedro Pichó y Rius en esta entrega de premios: ${ }^{50}$

Explica la estructura de esta rosa... / Mas jay! Nueva ilusión. Ni Flora misma / Más fresca, más lozana y delicada / Pudiera en sus vergeles producirla. / Tuyo es este portento, pincel sabio, / Que al vivo en tus floreros nos imita / Toda la gracia, la belleza toda / Que muestra el campo en la estación florida. / Tus hojas y tus flores embelesan, / Y tanta realidad halla la vista / En ellas, que el olfato seducido / La agradable fragancia solicita. / Mira, Naturaleza, en esos cuadros / Ríes tu abril, tu céfiro respira. / Venid, alegres Genios, coged flores / Que ni cierzo, ni sol jamás marchitan.

En 1799, una vez obtenidos todos los premios o recompensas "menores", Vivó solicitó tema para obtener el título de Académico de Mérito por la Clase de Flores, lo que suponía alcanzar el reconocimiento oficial de su arte. La Junta de la Academia le indicó que debía realizar para ello "un florero pintado al óleo [...] y un dibuxo adaptado a fábrica de terciopelo de un vestido completo de hombre del gusto más moderno". ${ }^{51}$ Sin embargo, parece que no debió entregar estas obras, pues cuando solicitó el grado de Académico Supernumerario por la Pintura en 1804, su petición no fue atendida por estar pendiente su nombramiento de un premio superior en otra disciplina, es decir, el de Académico de Mérito en la Clase de Flores. Como demuestra la solicitud del último nombramiento, Vivó aspiraba a convertirse en "pintor de Historia". Otro dato, inédito hasta el momento, que corrobora este deseo de reconocimiento fue su participación en el Concurso General de 1804, en el que optó, junto a Andrés Crúa, al premio de $1^{\text {a }}$ Clase de Pintura. ${ }^{52}$ Como asunto "de pensado" debía representar a "Los Reyes Católicos D. Fernando y $D^{a}$ Isabel, en compañía de su hijo el Príncipe D. Juan, dan audiencia pública en Barcelona a Chistoval (sic) Colon, descubridor del nuevo mundo: refiéreles éste sentado los sucesos de su viaje, y les ofrece varias producciones de aquel país que prueban su fertilidad y riqueza". El tema del "repente" fue "Huye Lot con su familia del incendio de Sodoma y su Mujer se convierte en Estatua de sal". El fracaso de Vivó en este caso fue importante, pues de los diecisiete vocales que debían adjudicar el premio, sólo recibió un voto.

Como sucedió con otros artistas de la época, la Guerra de la Independencia (1808-1814) debió suponer un paréntesis en la actividad de Vivó. Es posible que se dedicara a realizar encargos para particulares, como hacen suponer las obras que ahora se dan a conocer. También cesó su actividad en la Academia, pues no volvió a presentarse a los Concursos Generales celebrados en 1807 y $1810 .^{53}$ No obstante, una vez finalizado el conflicto, volvió a solicitar el título de Académico de Mérito en Pintura. La Junta le señaló como tema La expul-

${ }^{49}$ Las ideas estéticas contenidas en este tipo de fuentes fueron estudiadas por LEÓN TELLO, Francisco José; SANZ, María Virginia, 1979.

50 Don Pedro Pichó y Rius, Académico de Honor desde el 26 de octubre de 1795, fue presbítero, doctor, profesor de Matemáticas y Vicerrector del Real Seminario de Nobles de Valencia. Más tarde pasó a Xàtiva como Catedrático de Elocuencia y Director de los estudios públicos de la ciudad. Sus ideas estéticas son analizadas en el estudio ya mencionado de LEÓN TELLO, Francisco José; SANZ, María Virginia, 1979, pp. 251-254. En el caso del poema que se reproduce, juzgamos que corresponde a la tendencia del naturalismo platónico.

518 de diciembre de 1799. Acuerdos en limpio de Juntas Ordinarias desde 1787 hasta 1800, Manuscrito de la Academia de San Carlos de Valencia. En: ALDANA, Salvador, 1970, p. 96.

52 CONTINUACIÓN, 1805

53 Se ha podido corroborar esta información gracias a la consulta de las Actas manuscritas correspondientes a estos Concursos que se conservan en el Archivo de la Academia de San Carlos: 1807, 4 de noviembre. Valencia. Junta Pública de 1807. Continuación de las Actas de la Academia de las nobles Artes Establecida en Valencia con el título de San Carlos y relación de los Premios que se distribuyó en su Junta Pública de 4 de noviembre de 1807. Archivo de la Academia de San Carlos, de Valencia, Legajo 126/4/7 y Libro de actas de la Real Academia de San Carlos años 1801-1812. Junta general en 5 y 6 de Diciembre de 1810 y Junta Pública en 13 de diciembre de 1811. Según GARín, ed. 1993, p. 180, la fecha del último documento corresponde en realidad al año 1810 "error explicable [...] por el hábito de fechar con el número del año nuevo sin duda por haberse puesto en limpio esta acta muy avanzado aquél y a la vez que otras ya del mismo año". 


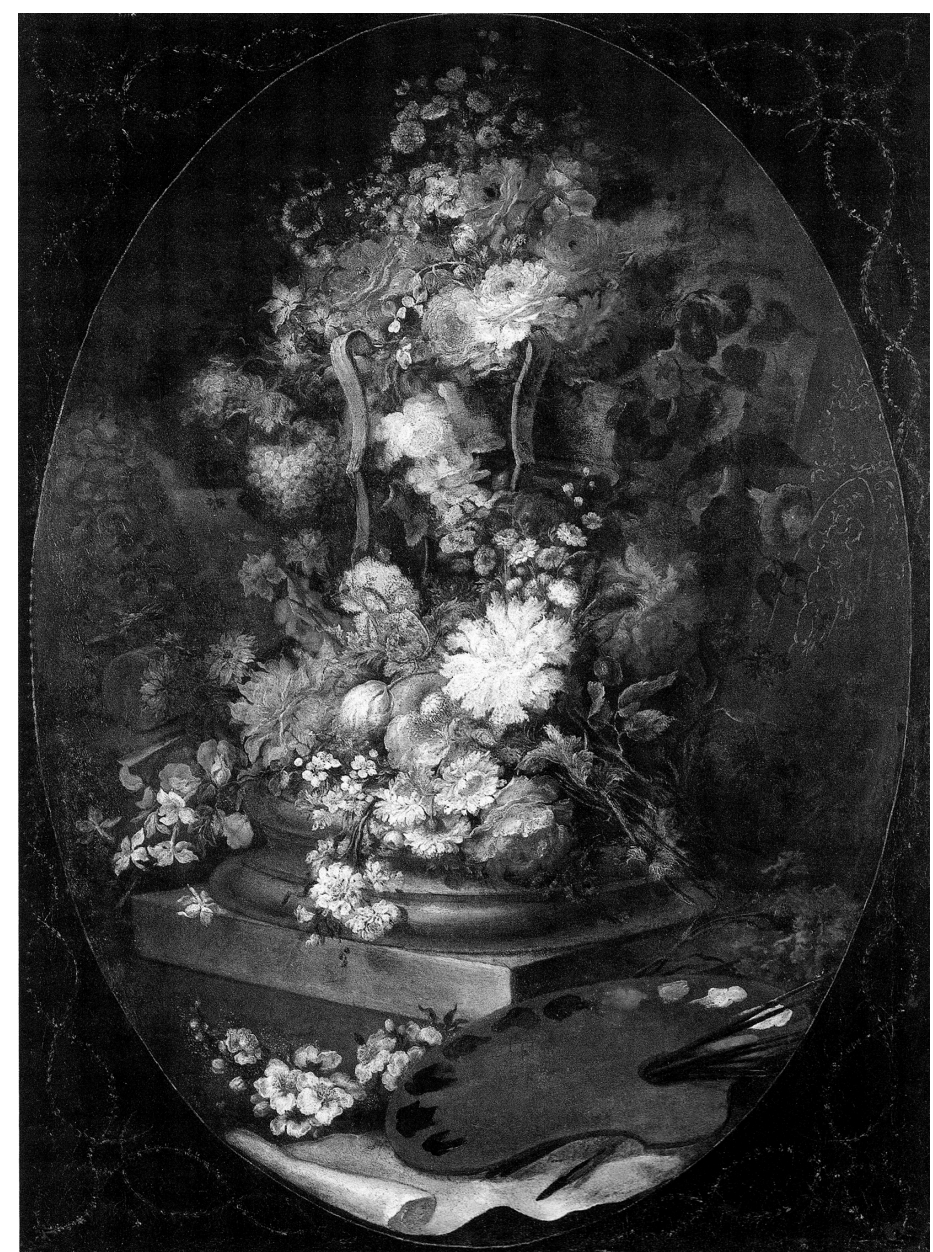

Fig. 7. Antonio Vivó, Bodegón de flores y paleta de pintor. Mercado artístico.

sión del Paraíso. Sin embargo, no consta que consiguiera esta distinción. Gracias a la información proporcionada por Almela y Vives a partir de una noticia del pintor Pedro Luis Bru, que era amigo de nuestro artista, sabemos que Antonio Vivó "debió fallecer de cólera en 1834". El mismo autor refirió las escasas noticias que existen acerca de su producción como retratista y pintor religioso. Él mismo vio "un retratito de una niña llamada Da María Candelaria Minguet y Montero" tocando una pandereta, realizado al óleo en 1821. En cuanto a la pintura religiosa, cita una Cena pintada igualmente al óleo que, en su juventud, pertenecía a "D. Mauricio Tomás Daroca y Llaneres, profesor de instrucción primaria de Valencia". Hace referencia, por último, a "unos Santos, por cierto muy mal pintados", realizados en 1832 para la ermita de Santa Bárbara de Moncada. ${ }^{54}$

El recorrido efectuado por la trayectoria académica de Antonio Vivó y los datos ofrecidos por los principales repertorios decimonónicos de artistas ponen claramente de manifiesto que su fortuna como pintor se debió fundamentalmente a sus composiciones de flores. Desgraciadamente, los dos floreros que se encontraban en el Museo de Bellas Artes de Valencia se perdieron hace bastante tiempo. Muy posiblemente fueran las obras que aparecen en el citado Inventario de las pinturas, flores pintadas y dibuxadas (1797-1834), con los números 12 y 52 . El primero correspondería al florero por el que consiguió el premio de $2^{\mathrm{a}}$ clase en el Concurso General de 1792 y el segundo, el que mereció el galardón de $1^{\text {a }}$ clase en el Concurso de 1798. Esta identificación se basa en la costumbre, extendida entre los artistas de la época, de entregar a la Academia las obras premiadas en estas convocatorias. En el Catálogo de los cuadros que existen en el museo de pinturas de esta capital de 1867, estos Floreros figuraban con los números 6 y 15, indicándose que el primero estaba realizado sobre lienzo y el segundo sobre tabla. ${ }^{55}$

El único lienzo de flores firmado por Vivó que se conoce hasta el momento se encuentra en el mercado anticuario madrileño (fig. 7). ${ }^{56}$ Este Bodegón de flores y paleta de pintor mide 85 x $63 \mathrm{~cm}$., superando así el tamaño de muchos de los lienzos conocidos de la Escuela valenciana de Flores. Está firmado en el extremo derecho de la superficie circular de la basa, donde se aprecia en letras rojas su nombre. A pesar de no estar fechado, el lienzo parece responder a un trabajo de madurez del artista. Desde el punto de vista formal, nos encontramos ante una adaptación novedosa, pero también deudora de las enseñanzas y los modelos de su maestro Benito Espinós, como sucede con las guirnaldas caídas en primer plano. De él también toma lo mejor de la producción de su última etapa caracterizada por una intensa iluminación. No obstante, la resolución técnica es más cuidadosa y la composición del lienzo de Vivó más compleja de lo habitual. En su ejecución al óleo, utilizó una pasta densa hábilmente perfilada mediante trazos muy precisos. En cuanto al color, supo combinar las tonalidades intensas con los medios tonos de manera sutil. Los distintos elementos de la obra están enmarcados

54 ALMELA Y VIVES, Francisco, 1960, p. 49.

55 CATÁLOGO, 1867, pp. 3-4. Ambos Floreros se encontraban en la portería.

${ }^{56}$ La obra se reproduce con este título en la página oficial del anticuario José Antonio Cámara. "Florero de Antonio Vivó" En: www.joseacamara.com/pintura_escultura.html (29-V-2006) y en el estudio de SÁNCHEZ, Andrés, 2008, p. 353, que ahora ampliamos. 
por un óvalo que acentúa su efecto decorativo. Del jarrón azul se aprecian dos de sus asas curvas, pero queda apenas visible por las flores que contiene y las que se distribuyen en su frente y su base. El recipiente se levanta sobre una basa de una columna de tonos dorados, cuya presencia recuerda a los criterios académicos. En efecto, este tipo de fragmentos arquitectónicos, junto a piezas de arqueología o pedestales de mármol, formaban parte de los nuevos elementos que los discípulos de la Escuela de Flores valenciana incorporaron a sus composiciones. Desde el punto de vista académico, estas alusiones a la Antigüedad clásica eran consideradas una parte fundamental de los "adornos de buen gusto" que debían acompañar a la representación de las flores. ${ }^{57}$ Estas últimas han recibido un tratamiento delicado que revela una observación directa de las especies ornamentales representadas. La mayor parte de ellas corresponden al repertorio habitual de los pintores valencianos, ${ }^{58}$ aunque Vivó ha incorporado flores nuevas. Pueden distinguirse más de veinte plantas distintas (fig. 8):

1. Rama de almendro (Prunus dulcis (Mill.) D. A. Webb = Amygdalus communis L.).

2. Claveles (cultivares de la especie Dianthus caryophyIlus L.).

3. Alhelí doble (Matthiola incana (L.) R. B. subplena.

4. Jazmines (Jasminum officinale L.).

5. Guisantes de olor (Lathyrus odoratus L).

6. Espino albar o majuelo (Crateagus monogyna Jacquin).

7. Margaritas (Leucanthemum vulgare Lam. = Chrysanthemum leucanthemum L.).

8. Distintas especies y variedades de rosas (Rosa sp.).

9. Arañuela (Nigella damascena L. semiplena).

10. Narciso de otoño doble (Narcissus $x$ incomparabilis Mill.).

11. Tulipán (Tulipa sp.).

12. Adormidera (cultivar de la especie Papaver somniferum L.).

13. Narciso trompón o de los prados (Narcissus pseudonarcissus L.).

14. Saúco (Sambucus nigra L.)?

15. Matricaria (Chrysanthemum parthenium (L.) Bernh.).

16. Bolas de nieve (Viburnum opulus L.).

17. Campanillas (Ipomoea tricolor Cav.).

18. Campana silvestre (Campanula persicifolia L.).

19. Amapola (cultivas de la especie Papaver rhoeas L.).

20. Trinitaria (Viola tricolor L.)?

21. Peonía (cultivar de flor doble de la especie Paeonia officinalis L.).

22. Ranúnculo asiático o francesilla (Ranunculus asiaticus L.).

23. Malvarrosa o malva real (Alcea rosea $\mathrm{L} .=$ Althaea rosea (L.) Cav.).

24. Lunaria o planta de plata (Lunaria annua L.).

25. Flores o ramas de peral silvestre (Pyrus communis L.)?

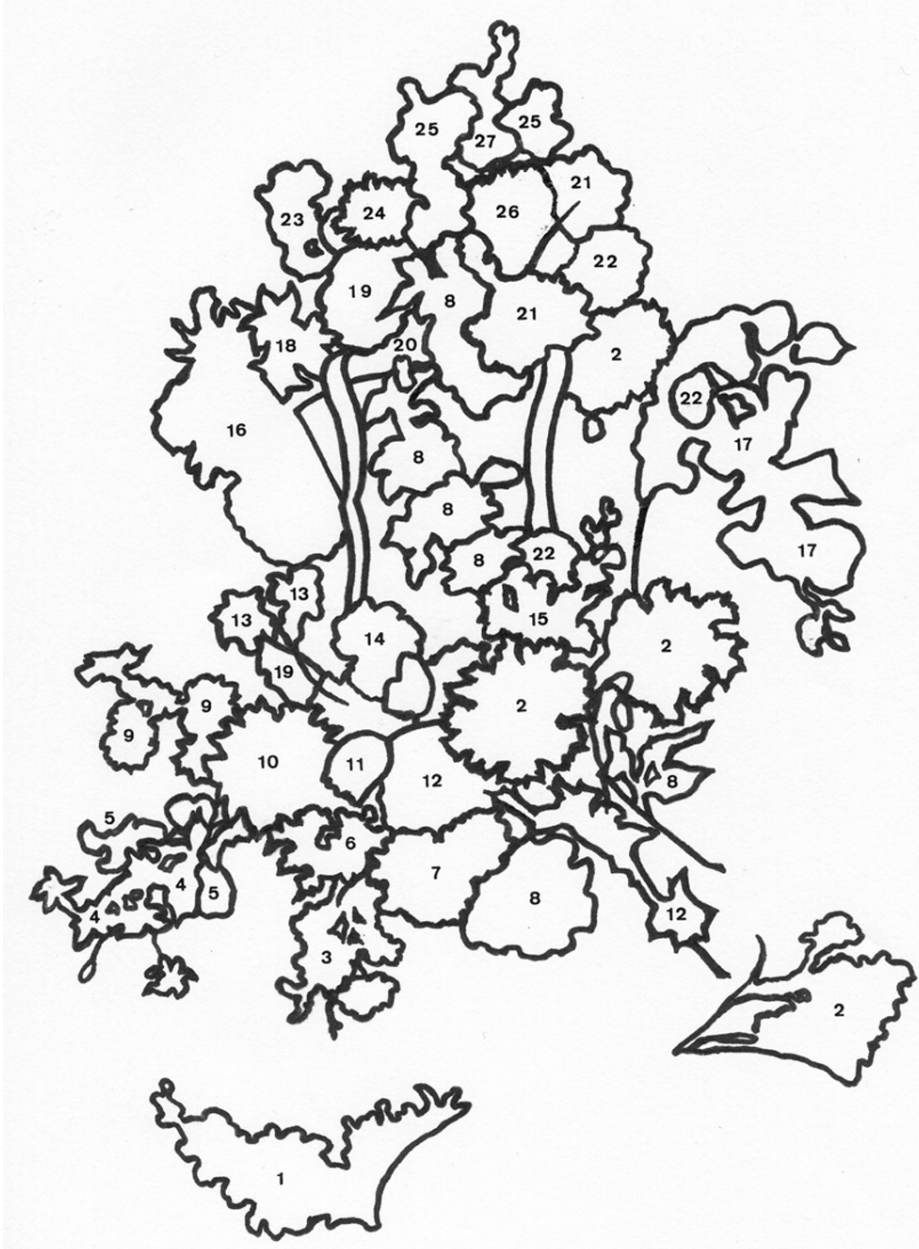

Fig. 8. María José López Terrada. Esquema con la identificación de las especies botánicas representadas en el Bodegón de flores y paleta de pintor. Mercado artístico.

26. Anémona de jardín (cultivar de la especie Anemone coronaria L.).

27. Forma doble del botón de oro común (Ranunculus acris L. plena).

El cuadro de Vivó incorpora además otros elementos singulares que podrían ampliar el sentido de la obra. Sobre el tallo del tulipán se posa una mariposa, elemento más propio de la pintura de flores del siglo XVII que de las composiciones españolas del momento. Por otra parte, en su mitad inferior, entre las delicadas flores del almendro y el clavel que cae sobre la basa de la columna, encontramos un papel parcialmente enrollado, similar a los utilizados en la Sala de Flores, dos dibujos que se sitúan a ambos lados del jarrón, un lápiz o carboncillo y una paleta con pinceles. Estos últimos útiles de pintura figuran en otras obras de la

57 Ver, entre otros, el estudio de LÓPEZ TERRADA, María José, 2001, p. 149.

58 Sobre esta cuestión, ver LÓPEZ TERRADA, María José, 2001, pp. 162-183. 
Escuela conservadas en el Museo de Bellas Artes de Valencia, como la Guirnalda de flores con una pintura en grisalla y amorcillos pintando (1801) de Miguel Parra y el Florero y niño pintor de Francisco Martínez, ca. 1844. ${ }^{59}$ Como señaló Pérez Sánchez, su presencia podría convertir un simple florero en una alegoría de la pintura. Según este autor, la inclusión de los útiles de dibujo y pintura "puede interpretarse como una alusión a que la naturaleza es la mejor pintura posible y cualquier otra aproximación ha de ser mera imitación de lo que ella ofrece". ${ }^{60}$ Independientemente de cual fuera la intención de Vivó al incluirlos en su composición, resulta evidente que la obra reúne los recursos más acertados de los pintores de la épo$\mathrm{ca}$, entre los que creemos que debería figurar.

A las obras mencionadas puede añadirse la Sagrada Familia que apareció en el mercado de arte en el año 2000 y que, por sí sola, merece un estudio aparte. Lamentablemente no puede ser reproducida en este artículo. ${ }^{61} \mathrm{El}$ cuadro está firmado en el ángulo inferior izquierdo, donde puede leerse: "Ant. Vivó fe $\mathrm{f}^{\mathrm{t}}$. La obra, un óleo sobre lienzo, no está en un estado óptimo de conservación, aunque se aprecia su buena técnica y colorido. Además, es muy interesante desde el punto de vista iconográfico. ${ }^{62}$ La escena está protagonizada por la Virgen, el Niño y San José, que se disponen sobre una tarima y dirigen su mirada hacia lo alto. En esta parte, entre nubes, se sitúa un rompimiento de gloria, un gran haz de luz, cuyos rayos son visibles y parecen concentrarse en la figura de la Virgen y, sobre todo, del Niño. Aparece en brazos de su madre y lo señala con el dedo. A la derecha, San José, caracterizado como un hombre joven, está arrodillado, con las manos en oración y lleva como atributo la tradicional vara florida. Esta composición se completa con una cartela en la parte inferior en la que puede leerse: "Ecce venio, ut faciam Deus voluntatem tuam". La frase se corresponde a un breve fragmento de la Carta a los Hebreos 10: 9: "Aquí estoy, oh Dios, para hacer tu voluntad", tomada del Salmo 40 (39), 7-8 y que en este pasaje es aplicado a Jesucristo. Su espíritu es mostrar que, para asumir la condición humana, hizo un acto de obediencia, siendo su única preo- cupación cumplir la voluntad de Dios Padre, disponiéndose a aceptar, anticipadamente, todo el sacrificio que habría de sufrir para redimir a los hombres.

Podemos concluir diciendo que, para alcanzar el objetivo propuesto en el presente artículo, hemos utilizado diferentes medios. Uno de ellos ha sido la revisión de las noticias proporcionadas por los estudios que se han ocupado de Antonio Vivó hasta el momento, completándolas con nuevos datos. Estos últimos proceden de notas de prensa, de manuscritos inéditos conservados en el Archivo de la Real Academia de Bellas Artes de Valencia y, sobre todo, de la consulta de las Actas que recogían los temas de los ejercicios y los premios otorgados en los Concursos Generales. Todo ello ha servido para reconstruir su trayectoria académica, que hemos ampliado además en sus comienzos con el análisis y reproducción de dos dibujos inéditos. Se han recogido asimismo las menciones de obras, tanto de flores -que se encontraban en el Museo de Bellas Artes de Valencia-, como de otros géneros: pintura de historia, religiosa y retratos. Por último se han dado a conocer dos óleos: una Sagrada Familia y la única composición de flores firmada localizada hasta el momento. En el examen de este Bodegón de flores y paleta de pintor se ha ofrecido un enfoque interdiciplinar puesto que, además de los aspectos formales y técnicos, se ha realizado una identificación botánica de las especies vegetales representadas. De esta forma ha sido posible reconstruir una parte de la producción artística de Antonio Vivó, que podrá continuar completándose en futuras investigaciones, salvándolo así del actual olvido.

\section{Bibliografía}

ALBA, Ester. La pintura y los pintores valencianos durante la guerra de la Independencia y el reinado de Fernando VII (1808-1833). Valencia: Servei de Publicacions de la Universitat de València, 2004.

ALCAHALÍ, Barón de. Diccionario biográfico de artistas valencianos. Valencia: Imprenta de Federico Doménech, 1897.

ALDANA, Salvador. Pintores valencianos de flores (17661866). Valencia: Instituto Alfonso el Magnánimo, 1970.

\footnotetext{
59 Para el análisis de la obra de Parra, ver LÓPEZ TERRADA, María José, 2016, y para la de Martínez, LÓPEZ TERRADA, María José, 2001, pp. 342-434, donde se ofrece una identificación botánica.

${ }^{60}$ PÉREZ SÁNCHEZ, Alfonso Emilio, 1996, p. 128.

${ }^{61}$ La fotografía la compré a Artprice, que no posee los derechos de reproducción de la misma. Fue presentada a subasta en Castellana 150, hoy desaparecida, el 20 de marzo de 2000. No obstante, quisiera mostrar mi agradecimiento a Caritina Martínez de la Rasilla y a Daniel Díaz, encargado de Pintura Antigua de Alcalá Subastas por intentar localizar al actual propietario para que confirmara o no su interés en la publicación de esta obra.

62 Sobre este tema pueden verse, entre otros, los estudios clásicos de MÂLE, Emile, ed. 1985 y RÉAU, Louis, ed. 1995-2000.
} 
ALDANA, Salvador. "L'Arxiu i la Biblioteca de l'Acadèmia de Santa Bàrbara i de la Reial Acadèmia de Sant Carles". En: ALIAGA, J. (com.). L'Acadèmia de Santa Bàrbara i la Reial de les Tres Nobles Arts de Sant Carles. Cent Anys d'Ensenyament de l'Art (1754-1854) (Catálogo de exposición). Valencia: Universitat Politècnica de València, 2004, pp. 33-51.

ALDANA, Salvador. "El saber enciclopédico. La biblioteca de la Real Academia de Bellas Artes de San Carlos". En: DE LA CALLE, Román (ed.). La Real Academia de Bellas Artes de San Carlos en la Valencia llustrada. Valencia: Universitat de València, 2009, pp. 277-290.

ALMELA Y VIVES, Francisco. "Notas y nótulas sobre artistas valencianos. Ossorio y Bernard apostillado por Estanislao Sacristán". Archivo de Arte Valenciano, 1960, n 31, pp. 28-49.

BOIX, Vicente. Noticias de los artistas valencianos del siglo XIX. Valencia: Imprenta de Manuel Alufre, 1887.

CATÁLOGO. Catálogo de los cuadros que existen en el Museo de pinturas de esta capital. Valencia: Imprenta de J. Doménech, 1867.

CAVESTANY, Julio. Floreros y Bodegones en la pintura española. Madrid: Sociedad Española de Amigos del Arte, 1936-1940.

CONTINUACIÓN. Continuación de las Actas de la Real Academia de las Nobles Artes establecida en Valencia con el título de San Carlos y relación de los premios que distribuyó en 9 de octubre de 1786. En la Oficina de Benito Monfort. Impresor de la Academia, 1787

CONTINUACIÓN. Continuación de las Actas de la Real Academia de las Nobles Artes establecida en Valencia con el título de San Carlos y relación de los premios que distribuyó en 24 de junio de 1789. En la Oficina de D. Benito Monfort. Impresor de la Academia, 1789.

CONTINUACIÓN. Continuación de las Actas de la Real Academia de las Nobles Artes establecida en Valencia con el título de San Carlos y relación de los premios que distribuyó en 6 de agosto de 1792. En la Oficina de D. Benito Monfort. Impresor de la Academia, 1792

CONTINUACIÓN. Continuación de las Actas de la Real Academia de las Nobles Artes establecida en Valencia con el título de San Carlos y relación de los premios que se distribuyó en 6 de noviembre de 1795. En la Oficina de D. Benito Monfort. Impresor de la Academia, 1796.

CONTINUACIÓN. Continuación de las Actas de la Real Academia de las Nobles Artes establecida en Valencia con el título de San Carlos y relación de los premios que distribuyó en su Junta pública de 6 de diciembre de 1798. En la Oficina de D. Benito Monfort. Impresor de la Academia, 1799.

CONTINUACIÓN. Continuación de las Actas de la Real Academia de las Nobles Artes establecida en Valencia con el título de San Carlos, y relación de los premios que distribuyó en su Junta pública de 12 de noviembre de 1801. En la Oficina de D. Benito Monfort. Impresor de la Academia, 1802

CONTINUACIÓN. Continuación de las Actas de la Real Academia de las Nobles Artes establecida en Valencia con el título de San Carlos y relación de los premios que distribuyó en su Junta pública de 4 de noviembre de 1804. En la Oficina de D. Benito Monfort. Impresor de la Academia, 1805.

DÍEZ, José Luis. Vicente López (1772-1850). 2 vols. Madrid: Fundación de Apoyo a la Historia del Arte Hispánico, 1999.
ESPINÓS, Adela. "Un inventario de dibujos conservado en la Academia de San Carlos de Valencia (17731821)". Archivo de Arte Valenciano, 1977, n 48, pp. 73-84.

ESPINÓS, Adela. Museo de Bellas Artes de Valencia. Catálogo de Dibujos. 3 vols. Madrid: Ministerio de Cultura, 1984

ESPINÓS, Adela. "Dibujos de flores aplicados al tejido en la colección de la Real Academia de Bellas Artes de San Carlos" y "Catálogo de óleos y dibujos". En: FRANCH, R. et al. Arte de la seda en la Valencia del siglo XVIII (Catálogo de exposición). Valencia: Fundación Bancaja, 1997, pp. 81-105 y pp. 177-271.

FELIU, Joan. La cerámica arquitectónica de Onda en el siglo XIX. Tesis doctoral. Castellón: Universitat Jaume I, 1998.

FELIU, Joan. La Arquitectura esmaltada. Cerámica arquitectónica de Onda en el siglo XIX. Ajuntament d'Onda. Regidoria de Cultura (Servei de Publicacions), 2001.

GARÍN ORTIZ DE TARANCO, Felipe María. La Academia Valenciana de Bellas Artes. El movimiento europeo y su proyección en Valencia. Valencia: Real Academia

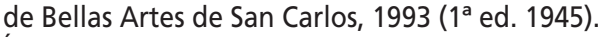

LEÓN TELLO, Francisco José; SANZ SANZ, María Virginia. La estética académica española en el siglo XVIII: Real Academia de Bellas Artes de San Carlos de Valencia. Valencia: Institución Alfonso el Magnánimo, 1979.

LÓPEZ TERRADA, María José. "El contexto histórico: la Escuela valenciana de Flores y la Botánica". En: FRANCH, R. et al. Arte de la seda en la Valencia del siglo XVIII (Catálogo de exposición). Valencia: Fundación Bancaja, 1997, pp. 49-61.

LÓPEZ TERRADA, María José. Tradición y cambio en la pintura valenciana de flores en la transición de la Ilustración al Romanticismo. 2 vols. Tesis doctoral. Valencia: Universitat de València, 1998.

LÓPEZ TERRADA, María José. "Nuevos datos sobre el pintor valenciano Francisco Michans Gargori (1777post 1837)". Archivo de Arte Valenciano, 2000, n 86 pp. 39-44.

LÓPEZ TERRADA, María José. Tradición y cambio en la pintura valenciana de flores (1600-1850). Valencia: Ayuntamiento de Valencia, 2001.

LÓPEZ TERRADA, María José. "La pintura de flores de Miguel Parra (1780-1846)". Archivo Español de Arte 2013, n 342, pp. 123-142.

LÓPEZ TERRADA, María José. "Entre el lenguaje alegórico y la pintura de flores: a propósito de una obra de Miguel Parra". Goya, 2016, n 356, pp. 238-251.

MÂLE, Emile. El Barroco. Arte religioso del siglo XVII. Italia, Francia, España, Flandes. Madrid: Encuentro (ed.), 1985.

OSSORIO Y BERNARD, Manuel. Galería biográfica de artistas españoles del siglo XIX. Madrid: Imprenta Moreno y Rojas, 1883-1884.

PÉREZ GUILLÉN, Inocencio Vicente. Cerámica arquitectónica valenciana. Los azulejos de serie (S. XVI-XVIII). 2 vols. Valencia: Generalitat Valenciana, 1996

PÉREZ SÁNCHEZ, Alfonso Emilio (com.). Naturalezas muertas y flores del Museo de Bellas Artes de Valencia (Catálogo de exposición). Valencia: Generalitat Valenciana, 1996.

PÉREZ SÁNCHEZ, Alfonso Emilio. "La pintura valenciana de flores". En: FRANCH, R. et al. Arte de la seda en la Valencia del siglo XVIII (Catálogo de exposición). Valencia: Fundación Bancaja, 1997, pp. 31-47.

RÉAU, Louis. Iconografía del arte cristiano. Barcelona: E Serbal (ed.), 1995-2000. 
SÁNCHEZ, Andrés. La pintura de bodegones y floreros en España en el siglo XVIII. Madrid: Fundación Arte Hispánico, 2008.

VEGA, Jesusa. "El inicio del artista. El dibujo, base de las artes". En: CARRETE PARRONDO, J. (com.). La formación del artista de Leonardo a Picasso. Aproximación al estudio de la enseñanza y el aprendizaje de las Be-
Ilas Artes. Madrid: Real Academia de Bellas Artes de San Fernando. Calcografía Nacional, 1989, pp. 1-29.

VIÑAZA, Conde de la (Muñoz y Manzano, Cipriano). Adiciones al Diccionario histórico de los más ilustres profesores de las Bellas Artes en España de D. Juan Agustín Ceán Bermúdez. 4 vols. Madrid: Tipografía de los Huérfanos, 1889-1894. 